\title{
DO CONCEITO DE FERTILIDADE AO DE SUSTENTABILIDADE
}

\author{
Gutemberg Armando Diniz Guerra ${ }_{2}^{1}$ \\ Maria de Nazaré Angelo-Menezes
}

\section{Introdução}

Entendendo conceito como a representação por palavras de um determinado objeto historicamente definido, todo ele se expressa dentro de um contexto, limitado pelo tempo e espaço. Essa compreensão exige, consequentemente, a sua utilização acompanhada de sua adequação aos seus limites históricos. O conceitoé, fundamentalmente, uma síntese de um determinado objeto, o que portanto, vem no final do processo de pensamento e não no começo, como observou Martins (apud Smith, 1990, p. 33). É a partir deste pressuposto que pretendemos refletir sobre o conceito de fertilidade da terra, utilizado amplamente na literatura agronômica, e nas abordagens em que se consideram as relações homem-natureza. Entendido genericamente como a capacidade dos solos em fornecer nutrientes para as plantas, o conceito de fertilidade dos solos vem de uma concepção estática. Desenvolvido nos países de clima temperado, sua aplicação nos trópicos apresenta limitações evidentes, conforme discutiremos a seguir.

\footnotetext{
${ }^{1}$ Engenheiro agrônomo, Doutor em Sócio-economia pela École des Hautes Études en Sciences Sociales, Paris, França, pesquisador e professor da UFPA / CNPq. NAEA e NEAF.

${ }^{2}$ Engenheira Agrônoma, Doutora em História Agrária pela École des Hautes Études en Sciences Sociales, Paris, França, pesquisadora e professora da UFPA / CNPq. NAEA e NEAF.
} 
O conceito tradicional de fertilidade ${ }^{3}$ passa a ser criticado a partir dos anos $70^{4}$ e começa a ser substituído pelo de sustentabilidade, vinculado ao funcionamento do ecossistema onde se inserem os vegetais como um de seus componentes. A proposição de uma abordagem mais holística é, de fato, produto da crítica às tecnologias propostas pela Revolução Verde e do crescente movimento ambientalista mundial dos anos 70 .

A adequação dos conceitos só tem sentido quando eles são insuficientes para explicar determinados fenômenos. Alguns efeitos indiretos significativos continuam a operar quando da utilização do conceito tradicional de fertilidade da terra, ou dos solos, quando da omissão da noção de que o ciclo de nutrientes nos trópicos tem uma dinâmica particular. Na prática, a fertilidade do solo em si mesma não faz sentido quando se trata de regiões como a Amazônica, por exemplo. Falar em solos fracos quimicamente distoa da pujança da floresta tropical presente na região. De igual maneira, apresentar trabalhos associando a fertilidade do solo a culturas específicas constitui-se em um limite, uma vez que nutrientes têm não apenas o solo como substrato e armazém por um determinado momento, estando presentes também nas plantas, no ar, na água e nos animais, ou seja, na biomassa e outros elementos que compõe o ecossistema.

Outro limite do conceito de fertilidade do solo se evidencia ao quantificarse a rentabilidade das culturas, tomando por base os preços recebidos pelos agricultores. Um deles está no fato de não incluir-se nos custos as perdas de nutrientes decorrentes do processo produtivo intensificado. Ao tornar o solo apto ao cultivo por práticas tradicionais como a queima, perde-se boa parte dos nutrientes por dispersão na atmosfera (Kato; Lato; Denich e Vvlek, 1999), por lixiviação, por percolação, por carreamento e por estar o solo exposto e sendo frequientemente revolvido, tornando-se vulnerável ao continuado processo de perdas. Estas perdas são mascaradas pelo fato de que os cultivos feitos imediatamente aos primeiros anos de desbaste da cobertura vegetal nativa apresentam um vigor e produtividade maiores de que nos anos posteriores, principalmente quando se utiliza a queima. Isto porque a mineralização imediata de alguns elementos torna-os disponíveis às plantas nos plantios iniciais, esgotando-se porém nos seguintes. Pode-se chegar, por esta via, a conclusões

\footnotetext{
${ }^{3}$ Estamos chamando de conceito tradicional de fertilidade da terra àquele que associa o solo a um armazem de nutrientes químicos, sem considerar as outras fontes e o ciclo dos nutrientes conforme proposto por ODUM (1988).

${ }^{4}$ Sobre estas críticas ver os anais dos Congressos Brasileiros de Agronomia - CBA, Encontros Brasileiros de Agricultura Alternativa - EBAA, e autores como Ana Maria Primavesi (1985); ALTIERI (1989) e outros.
} 
aparentemente corretas, mascarando os efeitos degradantes da atividade econômica. Quando não se queima, o processo de mineralização da biomassa é mais lento, fornecendo produtividades menores nos primeiros anos, oferecendo, porém melhores resultados a longo prazo.

Algumas conseqüências econômicas da conclusão pró-queimadas explicitada acima, podem ser vistas logo a seguir. A noção de acumulação econômica individual por parte de pequenos agricultores, derivada da quantificação por parâmetros exclusivamente econômicos da atualidade, sem considerar alguns aspectos da fertilidade do meio, prejudica e interfere na extrapolação de um modelo para a proposição de políticas públicas que favoreçam os processos de maneira coletiva, projetando-se na decretação a priori, da falência de uma categoria em construção: o campesinato amazônico.

Em outras palavras, o conceito de acumulação na trajetória dos camponeses estudados é freqüentemente mal aplicado, considerando-se o paradigma de fertilidade dos solos nos Trópicos Úmidos. A produção de textos de pesquisadores da região Amazônica (ver, por exemplo, Topall, 1990), contextualizados na evolução do conhecimento sobre pequenos proprietários relativamente bem sucedidos, individualmente, deixam de analisar os prejuízos e problemas repassados para o meio ambiente que só poderão ser avaliados posteriormente, pelos novos adquirentes. Se existe um processo de monetarização individual, ou mesmo de pequenos grupos, ele se dá a partir de um processo de desgaste dos recursos naturais, de dilapidação, portanto, que implode a faceta positiva do conceito de acumulação, concebido apenas do ponto de vista monetário.

Um outro problema é que a fertilidade é medida com uma perspectiva estática, ou seja, do solo em relação a uma cultura específica, dentro de uma tecnologia específica, em um sistema de produção dado e num tempo determinado. Medida numa perspectiva dinâmica, considerando-se um manejo diversificado em termos de culturas ou sistemas de produção, a fertilidade deve ser considerada como um atributo do conjunto - do meio - e está relacionada com as formas de utilização que dele se faz.

\section{Conceito de fertilidade}

O conceito de fertilidade pode ser expresso e entendido a partir de diversos ângulos, variando ao longo da história da humanidade. Se tomarmos uma das passagens mais conhecidas dos textos sagrados como, por exemplo, na Bíblia, o salmo 23, os vales e pastagens são associados à cor e ao relevo permitindo 
uma capacidade de suporte tranquilizadora do rebanho do bom pastor ${ }^{5}$. Os vales são lugares de acumulação de húmus e umidade, permitindo um aspecto vegetativo mais vigoroso das plantas. Dele utiliza-se a noção de fertilidade expressa no texto sacro. Não é de solo apenas que fala mas de férteis vales e de pastagens. Ora, o vale não pode ser entendido como um substrato qualquer. No seu conceito entra fundamentalmente um relevo que implica captação de água, acúmulo de nutrientes, desenvolvimento de flora e fauna diversos, fotoperiodismo e, como consequência de tudo isto, um clima e ambiente particulares. Afertilidade que podemos ver ali é, pois, derivada de um conjunto de fatores que favorecem o desenvolvimento dos animais e das plantas em interação.

Saindo dos textos sagrados, e tomando os registros históricos do Brasil colônia, pode-se fazer algumas reflexões a partir de uma das primeiras cartas enviadas ao rei de Portugal. Quando do descobrimento do Brasil, o escrivão Pero Vaz de Caminha observa, em sua carta, as virtudes da terra descoberta.

Tem, ao longo do mar, nalgumas partes, grandes barreiras, delas vermelhas, delas brancas; e a terra por cima toda chã e muito cheia de grandes arvoredos. De ponta a ponta, é tudo praia-palma, muito chã e muito formosa (Caminha, 1987, p. 96-97). A formosura da terra estaria no seu relevo, onde se observam barreiras, planícies (chã), e a presença de uma vegetação característica (praia-palma). Continuando a descrição das virtudes das novas terras descobertas, o escrivão prossegue acentuando a vastidão e presença de vegetais: Pelo sertão nos pareceu, vista do mar, muito grande, porque, a estender olhos, não podíamos ver senão terra com arvoredos, que nos parecia muito longa.

A terra, porém, para Caninha, não é apenas o solo:

Nela, até agora, não pudemos saber que haja ouro, nem prata, nem coisa alguma de metal ou ferro; nem lho vimos. Porém a terra em si é de muito bons ares, assim frios e temperados, como os de Entre Douro e Minho, porque neste tempo de agora os achávamos como os de lá.

Aguas são muitas; infindas. E em tal maneira é graciosa que, querendo-a aproveitar; dar-se-á nela tudo, por bem das águas que tem.

Para o escrivão português, a fertilidade - se é que assim podemos entender - estaria não apenas no terreno, no chão, mas nos ares, e nas águas.

${ }^{5}$ O senhor é meu pastor, nada me falta. Ele me faz deitar em verdes pastagens (Salmos 23, 1-2). 
A influência religiosa no entanto permanece sempre que se fala do processo de colonização. É comum a expressão vocação das terras, vocação agrícola, reificando-se a terra como tendo uma destinação dada por Deus, ou tendo sido chamada para cumprir uma determinada missão. No fundo, é a cristianização como elemento de dominação que se expressa nos vocacionamentos da terra, ou a expressão positivista de progresso, de civilização, de domínio do espírito sobre a natureza. O problema desta abordagem é que ela é excludente, unilateral. As terras têm uma vocação ou outra, ou serve para pecuária ou para fruticultura, ou para reflorestamento. A adjetivação em que se absolutiza a vocação das terras é o que vamos encontrar em vários textos oficiais e acadêmicos.

É a partir das experiências de Liebig (1803-1873), que a fertilidade do solo passou a ser tratada como o estoque de nutrientes nele contida, determinando a necessidade ou não de adição de produtos químicos, incorporando-se os principais elementos necessários ao desenvolvimento das plantas instaladas (Coelho e Verlengia, s/d). Esse tipo de tratamento generalizou-se ao longo dos últimos séculos, transformando os vegetais em projetos (plantas) industriais, considerando-se apenas os seus aspectos finalísticos, independente da sua relação com os ecossistemas nos quais estão situados e interagindo. A fertilização das plantas passou a ser encarada como um fator que se resolve a partir de fora do ecossistema e não dentro dele mesmo. Este comportamento metodológico desnaturalizou os vegetais domesticados no sentido de que suas funções passaram a ser determinadas não por suas características intrínsecas mas pelas necessidades daqueles que os utilizam.

Mede-se, normalmente, a fertilidade natural dos solos pelos valores da capacidade de troca de cations (CTC), de enxofre e de alumínio, principalmente quando submetidos à maior ou menor lixiviação das bases em função da textura dos solos (Moreira, 1960).

\section{Clima, Solo, Vegetação e o Homem interagindo}

Antigos e novos dados sobre clima, solos e vegetação mostram que áreas muito extensas da Amazônia não são iguais aos ecos sistemas esgotados da Floresta Tropical de Terra Firme e de seus arredores, mas, ao contrário, são habitats ribeirinhos e de terra firme sazonais, ricos em nutrientes, formados por sedimentos recentes e espessos, geologicamente heterogêneos.

Ainda que os etnológos classifiquem as populações da Amazônia vivendo na Floresta Tropical Úmida sempre verde, na realidade a maioria dos habitantes 
atuais da Amazônia, que foram estudados intensivamente, vivem em climas sazonais de menor pluviosidade, geralmente com vegetação predominantemente de Florestas semidecíduas e de Savanas. Tais climas não são o que se considera classicamente como climas de Floresta Tropical Úmida sempre verde .

O clima sazonalmente seco e sua vegetação não são recentes na Amazônia. Eles têm sido um bioma adaptativo em si, desde a pré-história antes mesmo da ocupação humana. Eles não são meramente resultado da degradação do meio ambiente após conquista. Evidências de pesquisas em perfis de polén (Absy, 1979 e1985; Bush et al. 1989, apud Roosevelt, 1991, p. 110) e em imagens de satélite (Roosevelt, 1991, p. 111), indicam que tais climas parecem ter sido algo mais extenso em tempos pré-históricos do que hoje. Achados arqueológicos macrobotânicos documentam, também, a presença de savana e de floresta-galeria durante quatro mil anos de pré-história (Garsom, 1980; Roosevelt, 1989b; Smith \& Roosevelt, 1985, apud Roosevelt, 1991, p. 112).

Essas informações científicas contrariam o quadro usualmente fornecido na literatura que indica predominância de solos senis e lixiviados, datados do Terciário ou até mesmo mais antigos. Atualmente sabe-se que os solos da Amazônia derivam, em grande parte, da natureza e da origem do material ancestral e da história das formações superficiais. Outras pesquisas estabeleceram que as formações superficiais de áreas extensas da Bacia Amazônica datam do Pleistoceno tardio e do Holoceno e que contêm sedimentos recentes erodidos, ricos em elementos intemperizáveis.

Grandes áreas de terra firme no AltoAmazonas, no sul e no BaixoAmazonas tem extensas camadas de rochas do Cretáceo e do Carbonífero, com alto conteúdo de elementos intemperizáveis. Existem, também, grandes diques intrusivos de diabásio e de outros tipos entre as rochas cristalinas ácidas (Derby, 1987; Klammer, 1984; Putzer, 1984; Allen, 1968, apud Roosevelt, 1991, p. 110). Sob clima tropical com sazonalidade, tais rochas produzem solos do grupo Alfisol ou Molisol, e não Oxisols e Utisols. Esses solos Amazônicos são mais comparáveis aos solos da costa do Golfo do México, do Yucatan, do sudeste Asiático e do Mediterrâneo, do que aos solos da Floresta Tropical Úmida, desenvolvidos a partir das rochas ácidas cristalinas da América do Sul.

\footnotetext{
${ }^{6}$ Richards (1952). Caracteriza esse clima como de intensa lixiviação química estabelecida para tal modelo de paisagem (apud Roosevelt, 1991, p. 109).
} 
Os solos hidromórficos da Amazônia não são encontrados somente nas planíces inundáveis, mas também, em numerosos terraços fluviais elevados do Pleistoceno tardio e do início do Holoceno. Existem grandes extensões de depósitos de sedimentos espessos e recentes, formados entre o início e o meio do Holoceno, a partir de produtos oriundos de intensa erosão nos divisores de água entre os Andes e a Amazônia (Campbell \& Frailey, 1984; Campbell, Frailey \& Arellano, 1985, apud Roosevelt, 1991, p. 110).

Desse panorama fisico-químico, por que esses tipos de solos teriam sido limitantes para o desenvolvimento cultural das populações amazônicas, se solos semelhantes não foram limitantes ao desenvolvimento cultural da Bacia do Nilo e em de outros lugares semelhantes?

Evidentemente que em termos de ecologia humana evolutiva as abordagens não são comparáveis. Nem no paralelo, igualmente sem sentido, considerandose como o único habitat funcional do Nilo pré-histórico o deserto interfluvial dessecado, omitindo-se a fértil planíce de inundação. Quanto aos solos, a diferença entre a Amazônia e o mundo refere-se a extensão que nesse caso é muitas vezes maior em tamanho e proporção.

As novas descobertas geomorfológicas mostram que a velha afirmação de que $98 \%$ são solos senis e pobres em nutrientes está muito longe da realidade. AAmazônia apresenta além de uma extensa área, as ricas planíces pleistocênicas e holocênicas amazônicas circundadas por florestas de terra firme, das quais as melhores são apropriadas para a agricultura intensiva e as piores para o cultivo de corte-e-queima e forrageio.

A utilização da expressão Floresta Tropical Úmida para descrever habitats criou um problema interpretativo para a antropologia amazônica, devido às associações feitas sobre as conseqüências desenvolvimentistas da adaptação humana a esse tipo de ambiente.

O que a teoria do desenvolvimento cultural daAmazônia tenta demonstrar é que os recursos das várzeas produtivas da Amazônia encorajaram o desenvolvimento precoce de forrageio intensivo, do estabelecimento sedentário, de fabricação de cerâmica e de horticultura. Eram áreas bastante ricas e substanciais, circundadas por extensas florestas habitáveis, suplantando os terrenos desérticos, o que permitiu que a Bacia Amazônica pudesse absorver crescimento populacional humano por um período longo (Roosevelt, 1980) . Em termos préhistóricos tardios, os tipos de sistemas de subsistência e de padrões demográficos característicos das civilizações que desenvolviam-se na Amazônia, e as 
sociedades complexas ali formadas, ainda estavam em ativa expansão quando foram interrompidas pela ocupação européia.

As pesquisas que buscam explicar as possibilidades adaptativas da Amazônia colocam como evidências os biomas amazônicos sazonais, ricos em nutrientes, com implicações adaptativas muito diferentes daquelas do bioma clássico, pobre em nutriente, da floresta tropical. Aágua abundante e os solos produtivos dessas áreas dão a elas uma maior biomassa de plantas e de animais aproveitáveis pelo homem, do que todos os solos lixiviados da floresta tropical de interflúvio, geologicamente pobres em substratos.

Os habitats ribeirinhos e de terra firme ricos em nutrientes são compostos de recursos vegetais e animais em abundância para a subsistência humana não podendo ter sido uma barreira para o forrageio, o sedentarismo, o crescimento populacional e a agricultura. Esses habitats evidenciam tipos de ambientes nos quais podem ter florescido grandes civilizações e muitos reinos, sendo, verdadeiramente, locus onde as sociedades complexas indígenas da Amazônia se desenvolveram. Portanto, existem razões para considerar esses habitats propícios para a evolução social na Amazônia.

\section{A aplicação do conceito de fertilidade na Amazônia ao longo da História}

Nos textos sobre a Amazônia, a fertilidade aparece frequentemente associada à dinâmica dos fluxos dos cursos d'água, e às alterações de temperatura, implicando em aspectos positivos da vegetação. Volume de água e sedimentação em uma vasta planície, com baixo índice de declividade, por exemplo, são referências dos textos de autores importantes . Outros aspectos como pluviosidade e a temperatura elevada estimulam a concentração de sacarose no colmo da planta cultivada na Amazônia (Angelo-Menezes, 1999, p. 29).

A floresta amazônica situa-se entre os trópicos, razão porque goza de condições climáticas particulares baseadas sobre uma incidência de radiação solar constante ao longo de todo o ano. A variação de temperatura é fraca e seus extremos situam-se entre 15 e $35^{\circ} \mathrm{C}$.

\footnotetext{
${ }^{7}$ Dados etnorustóricos e arqueológicos mostram que essas sociedades complexas tinham domínios culturais tão grandes ou até mesmo maiores que os de muitos Estados pré-industriais do Velho Mundo, tais como a civilização Mycena ou a do Vale do lndus (Roosevelt, 1980).

${ }^{8}$ Conforme David (1964) ; Oltman (1967) e Sioli (1984) o rio Amazonas é o maior rio em volume d'água do mundo, com cerca de 175.000 metros cúbicos por segundo desaguando no mar. Os seus mais de $5.000 \mathrm{~km}$ navegáveis estão dentro de uma planice sedimentar com cerca de apenas 30 metros de declividade (apud Nunes de Mello e José Alberto Sampaio, 1993. p. 11. Ver esta citação em Angelo-Menezes, 1999, p. 28).
} 
A umidade, fator importante para a circulação química dos minerais e a decomposição da matéria orgânica, permite a criação de um ambiente mais ou menos invariável, excelente para o desenvolvimento de uma grande diversidade biológica. A floresta amazônica, em razão de sua considerável extensão, permite trocas de massas de ar no nível planetário, sendo influenciada desde o sul por correntes frias que se espalham durante o inverno (Waischet, 1987), sofrendo, igualmente a influência de ventos tropicais (Klinge, Furch y Junk, 1987).

Na região amazônica, a pluviometria anual é de aproximadamente 2500 $\mathrm{mm}$, podendo atingir $5000 \mathrm{~mm}$ aos pés dos Andes. Os Andes e o Equador são as regiões mais irrigadas, com aproximadamente $6000 \mathrm{~mm}$ (Dominguez, 1980). No Sul daAmazônia existe uma estação de três meses sem chuva, mas este nível baixa gradualmente à medida em que se vai para o norte, até atingir $3500 \mathrm{~mm}$ na região do Rio Negro (Klinge, Furch y Junk, 1987). Pesquisas sublinham que a metade da água da Bacia Amazônica provem do Oceano Atlântico, graças ao sistema de circulação atmosférica tropical, e a outra metade de chuvas produzidas por evapotranspiração. Este processo estabelece um regime hídrico fraco, no qual prospera a cobertura vegetal. Disso resulta que os cortes e queimas da floresta destroem o mecanismo de evapotranspiração e simplificam o equilíbrio hídrico a tal ponto que as precipitações podem tornar-se iguais ao esgotamento, pois a vegetação, através da folhagem, intercepta a água da chuva que evapora e retorna à atmosfera para cair de novo em precipitações (Salati, 1987).

Os solos que resultam das condições acima descritas correspondem à uma grande parte e o mesmo fenômeno se produz em outras regiões do trópico úmido. Estes tipos de solos apresentam níveis de alumínio tóxico, fracas reservas de potássio, forte fixação de fósforo e uma fraca capacidade de troca, e por conseguinte, uma fertilidade desfavorável à agricultura. Nestas circunstâncias, a presença da floresta se explica por um processo de adaptação da vegetação e por uma rápida circulação de minerais provenientes diretamente da chuva. Assim, as plantas captam minerais também da biomassa da floresta e não apenas do solo. O ciclo da matéria e da energia se aceleram criando um circuito fechado onde a perda da matéria é mínima. É assim que $75 \%$ do potássio, $40 \%$ do magnésio e $25 \%$ do fósforo captados pelas plantas provêm da água da chuva (Lugo, 1982).

As condições físicas não são homogêneas nas florestas tropicais, da mesma forma que a vegetação não depende apenas do clima e do solo. Existem características gerais de base, como as raízes tabulares das grandes árvores, as raízes adventícias das palmeiras, as flores que saem diretamente do tronco e dos 
ramos (caulifloras) como o cacau e sobretudo as epífitas. Aestratificação vertical composta das árvores de tamanho mais ou menos idêntico é um outro fenômeno comum nas florestas pluviais.

As inundações são, também, fenômenos considerados positivos para a manutenção da fertilidade do solo.

Mesmo quando o fluxo da maré era baixo e não cobria toda a superficie, as águas penetravam nas várzeas através de rios e igarapés mantendo a umidade das terras, mesmo nas épocas mais secas do ano. Estes mesmos rios e igarapés facilitam a drenagem do solo, evitando o seu encharcamento. Esta rede natural de acesso por via fluvial, canalizando o fluxo e o refluxo da maré, facilitava o transporte da cana de açúcar, que era um produto volumoso e pesado. (O volume de água é oriundo dos 2.000 mm de chuva que caem anualmente e escoa das terras planíssimas, e também dos 8000 mm, ou mais, de água levadas à terra pela maré. Além de que todas as terras são cortadas por inúmeros rios, furos e igarapés) (Anderson, 1991).

Na verdade, esta é uma descrição de parte da dinâmica do ciclo de nutrientes que vem não apenas da qualidade química do solo em si mesmo, mas de sua interação com as águas e outros elementos.

A histórica inadequação dos métodos e práticas agrícolas no Vale do Tocantins, primeira das áreas ocupadas intensamente pelos portugueses no início da colonização amazônica, é uma das hipóteses para o atraso em que se manteve a agricultura. Empregados sem considerar os componentes do clima e solo, e o distanciamento cultural dos povos indígenas, o resultado foi o enfraquecimento do comércio dos derivados da pecuária e dos cultivos do café, tabaco e algodão, aliados aos gêneros extrativos como a baunilha e a salsaparrilha (Códice 343 (1795 à 1803) - AHUM - Lisboa). O projeto econômico português acabou comprometendo a regeneração dos recursos da floresta devido a um primeiro momento econômico baseado na intensificação das atividades extrativistas, e num segundo momento pela experimentação desses produtos visando a transição para sistemas agro-extrativistas. O aprendizado desta relação necessária com o meio ambiente e a adaptação dos conhecimentos à realidade regional foi inevitável.

Neste contexto as modificações dos ecossistemas naturais foram consequências das experimentações dos novos métodos agrícolas, tendo em vista o consórcio de produtos extrativos e agrícolas, resultando numa tipologia com espécies que desapareceram, e outras que foram exploradas intensamente. 
Entre essas tipologias, o primeiro sistema é caracterizado por espécies dizimadas devido às relações sociais que transformaram o índio em escravo. Os saberes índigenas foram esquecidos ao serem relevadas as práticas de manejo de sucessão dos recursos florestais. Somente algumas práticas, como a coivara, foram absorvidas. As demais, apesar de serem extremamente ricas, acabaram não sendo assimiladas pelos novos habitantes da Amazônia. Um outro fator para explicar esse tipo de sistema caracterizado por espécies que desapareceram está relacionado com as técnicas extrativas substituídas por práticas agrícolas, com a introdução do arado de aiveca. Essa inovação técnica tão importante na produção européia, ao ser introduzida no Grão-Pará, desencadeou um processo de desestruturação de todo o sistema produtivo, representado na literatura pela desestruturação do solo.

A Amazônia de hoje é formada do processo de adaptação, com sua diversidade de gêneros de vida intimamente associados à diversidade ambiental, correspondendo a formas de vida de uma população igualmente diversificada. O meio bioclimático, a cobertura vegetal, os solos de várzeas e terra firme, os rios, lagos, igapós e igarapés revelam uma forte influencia sobre o ritmo da vida e sobre a natureza da atividade humana. Desta variedade ambiental nasceram as particularidades que diferenciam os grupos do sistema de adaptação sustentável e coerente com sua estrutura cultural.

Deve-se levar em conta que um dos elementos importantes para a desestruturação do sistema ecológico foi, sem dúvida, a lógica do capital suplantando a lógica da sustentabilidade ecológica. O fundamento básico da desestruturação dos ecos sistemas amazônicos é a velocidade excessiva de sua utilização, imobilizando a recomposição, ou seja o tempo (sistema) no qual se realizam as atividades, mas também a forma inadequada como ele, o novo sistema, é praticado, dilapidando os nutrientes.

O extrativismo intensivo gerou desequilibrios irreversíveis em ecos sistemas que tinham sido sustentados durante milênios pela economia indígena. A salsaparrilha desapareceu pela forma do corte que destruia a mamapioca que era o material vegetativo da planta, e o cravo que por ser extraído das cascas de árvores abatidas, desencadeou o processo de extinção da espécie.

Para entender-se a História Agrária da Amazônia é preciso reconhecê-la nos seus recortes heterogêneos que comportam diferenças notáveis de um extremo a outro. Daí a importância de estudos de seus sistemas agrários ${ }^{9}$ para não incorrer

${ }^{9}$ O sistema agrário exprime, particularmente, a interação entre um sistema biológico representado pelo meio natural e um sistema sócio-cultural; d. Angelo-Menezes, 1999. 
em generalizações que tornam a Amazônia desprovida de particularidades, de elementos diferenciais, tais como sociedades e instituições.

A generalização sobre diferentes realidades caracteriza o regime colonial implantado na região, cujos interêsses daquela administração era a passagem da economia natural à economia monetária, e que fez uso de relações sociais de produções pré-capitalistas tendo como fim uma agricultura de mercado. A integração da região amazônica em um mundo de trocas capitalistas desestruturou o sistema agrário estabelecido.

Foi relegado a segundo plano o aproveitamento regular e continuo da floresta que era feito através de práticas produtivas ecologicamente sustentáveis, estabelecidas a partir de um critério social diferente da lógica mercantil. Nessa diferença da lógica de organização venceu o colonizador que desconsiderou a estruturação de micro espaços que identificam a Amazônia. Esta visão holística que considerou a totalidade confundindo o entendimento de que cada ponto do espaço é particular, desencadeou uma sucessão de procedimentos prejudiciais ao meio ambiente.

Contemporaneamente se repetem os mesmos erros da época colonial devido ao planejamento regional e das políticas públicas que esquecem que esta regionalização é constituída numa base territorial bastante complexificada. Seja do ponto de vista físico ou social, as organizações funcionam a partir de estímulos movidos por interesses diversos, levando a processos espaciais vários, tributários, por seu turno, de distintos processos de regionalização.

Estudos contextualizados sob forma de história-problema pode conduzir a uma delimitação do campo agronômico e do conhecimento dos sistemas agrários do periodo colonial, sujeitos às mudanças e fragilidades, sobretudo quando pressionados ou subordinados aos ritmos de exploração e uso ditados pelo capital mercantil. Os resultados dessa compreensão podem auxiliar na construção do que ocorre hoje neste mesmo espaço.

Aconcepção sobre Bacia Amazônica no seu conceito espacial distingue uma temporalidade diferenciada em sua concretização histórica que restringe as possibilidades de análises da questão ambiental e do entendimento contemporâneo da natureza. AAmazônia como uma vasta região heterogênea devido à sua condição hidrográfica, orográfica e botânica proporcionou modos de vida diferentes, resultantes de adaptações aos seus respectivos ambientes graças à distribuição dos recursos naturais e da influência que esses ambientes exerceram sobre os grupos sociais. 
O meio bioclimático, o revestimento vegetal, os solos de várzea e terra firme, os rios, os lagos, paranás e igarapés têm demonstrado forte influência no rítmo de vida e na natureza da atividade humana. Desta variação ambiental surgiram as particularidades que diferenciam os grupos, criadores de sistema adaptativo sustentável e coerente com seu arcabouço cultural.

Fazendo o contraponto com a colonização dos vales andinos, observa-se que a história agrária destes vales reside, em parte, na artificialização de um ambiente difícil. Dados demográficos diferem pouco entre 1560 e 1750, o que demonstra que existiu uma recuperação da queda populacional do século XVI, provocada quando da chegada dos colonizadores (Sallis, 1987). A paisagem agrária resulta da atividade organizada e das dificuldades ambientais que foram contornadas, onde a dinâmica dos sistemas agrários destes vales e bacias é marcada simultâneamente por rupturas e continuidades.

As diferenças econômicas, políticas e culturais brasileiras foram determinadas pela chegada dos europeus. Na época colonial, o país era dividido entre o Estado do Brasil e o Estado do Grão-Pará e Maranhão e a história agrária não tinha em comum senão as relações de produção e a divisão do trabalho escravo entre índios e africanos.

Para o Estado do Brasil, a política estava voltada para a produção da cana de açúcar (Saccharum officinarum), a pecuária e a atividade mineral enquanto que no Estado do Grão Pará e Maranhão, o estímulo à produção do espaço estava baseado sobre o comércio das drogas do sertão, denominação dada pelas autoridades, comerciantes e colonos às plantas extraídas da floresta como o cacau (Theobroma cacao), a canela (Cinnamomum sp.), a salsaparrilha (f)milax paPivacea), o cravo da índia (Gypsophila paniculata), o anil (Indigofera timetoria), a baunilha (Vanilla planifllia), o óleo de copaíba (Copaifera multjjuga), o breu (protium sp.) e a andiroba (Carapa guianensis)(Angelo-Menezes, 1998).

Os primeiros efeitos da inadequação da utilização dos recursos naturais vem desta época.

\section{Questionando o conceito de fertilidade aplicado na Amazônia}

Recentemente, a proximidade de pesquisadores científicos junto a organizações camponesas se, de um lado, possibilitou a interação e contribuições que verificamos em trabalhos anteriores (Guerra, 1999; Ângelo-Menezes, Reynal e Wambergue, 1989), de outro permanece com lacunas a serem preenchidas. Uma delas se dá no plano conceitual, em que a aplicação indiscriminada de 
noções e conceitos gerados em realidades distintas, sem uma crítica que permita os devidos ajustes, deixam vulneráveis os conteúdos ali estudados. Neste texto nos dispomos a uma discussão sobre o conceito de fertilidade e como ele tem sido aplicado na reflexão de temas amazônicos.

O termo acumulação começou a ser utilizado na região de Marabá a partir de um estudo feito em uma localidade da Transamazônica ${ }^{10}$. É utilizado para explicar a resistência alcançada por alguns agricultores e o seu acesso à terra através da compra por recursos auferidos em etapas anteriores à de pequenos proprietários (arrendatários ou agregados). Ele continua sendo utilizado, indiscriminadamente, para falar de poupanças temporárias e táticas de sobrevivência passando porém uma idéia de transformações onde o acesso ao recurso dinheiro passa a ser mais ou menos importante, enquanto outros diminuem em presença e status no sistema:

A mata, que ocupa ainda metade do lote perde importância dentro do sistema de produção: as castanheiras começam a morrer dentro das áreas de roça e a caça já não é tão abundante quanto no início (Reynal et alii, s/p. 27).

Com alguns anos de trabalho esse agricultor acumula, seja via lavouras brancas, ou através do início de criação de gado, o dinheiro suficiente para adquirir um lote próprio (Idem, p. 25).

As alterações no meio físico e socio-econômico permitindo o sucesso de alguns produtores em suas trajetórias é interpretada como um processo de acumulação quando a nosso ver ela não passa de estratégias de monetarização do trabalho de uma categoria que prioriza o elemento criação bovina em sacrifício da unidade diversificada, trocando a segurança que poderia dali advir por uma liquidez, ou construção de uma renda, uma vez que não se processa a partir da expropriação de mais valia, e sim de entesouramento a partir do trabalho. Se pensamos em acumulação como o processo de reprodução simples descrito por Marx, em que entram combinados como inputs os meios de produção (terra, trabalho e capital) e saem como resultados os mesmos entrantes acrescidos de um excedente que pode ser reaplicado em um segundo momento, reproduzindo novos meios e um novo excedente, não é isso o que tem se passado entre os agricultores na Amazônia. O meio terra se degrada de tal maneira que o que se consegue no final são produtos em que o desgaste teria que ser reposto em níveis que a reprodução encarece a tal ponto que o excedente não é capaz de

${ }^{10}$ TOPALL (1990). Componente do Laboratório Sócio-Agronômico do Araguaia Tocantins - LASAT que iniciou a fase de diagnósticos da região abrangida nas pesquisas do Centro Agroambiental do Tocantins - CAT. 
cobrir estes custos. Poder-se-ia argumentar que o valor da terra aumenta no mercado deste bem, pelo trabalho nele inserido, assim como nas condições externas que lhe vêm a ser agregados (estradas, benfeitorias, proximidade dos centros urbanos). Isto porém justifica apenas a possibilidade de convertê-la em dinheiro e não em que a reprodução física e social daquele que chegou naquele ponto seja possível a partir dali.

Os conhecimentos sobre a manutenção da disponibilidade dos nutrientes nos solos amazônicos evoluiu consideravelmente. Alterou-se completamente a noção de que os solos melhorariam com a implantação de pastagens e de que permaneceriam sustentando-se indefinidamente como afirmado na década de 70 por cientistas da rede oficial de pesquisa (Falesi, apud Fearnside, 1989, p. 204).

Os trabalhos científicos em geral, e de pesquisadores do Centro Agroambiental do Tocantins, em particular (Fabri, Veiga Jr. e Ozier-Lafontaine, 1991, p. 145; Cardoso, Martins e Veiga Jr. 1991, p. 103), utilizam o conceito de fertilidade química do solo, tomando-se como premissa a sua construção feita na Europa, de clima temperado, em que a dinâmica dos nutrientes é completamente diferente dos climas tropicais, conforme explica Odum (1983, p. 133). A baixa pluviosidade e o tempo de pousio obrigatório pelas baixas temperaturas, nos países temperados, mantêm os nutrientes praticamente produzindo o seu ciclo praticamente no mesmo espaço físico. $\mathrm{O}$ conceito de fertilidade é construído, neste caso, como um atributo estático e inerente ao solo, mesmo quando alterações ocorrem a partir de outros elementos do sistema. As perdas por corte de florestas ou pela renovação de cultivos são reincorporadas, significativamente, através dos restos deixados sobre o terreno, o que em climas tropicais são arrastados pelas águas. Se feito o questionamento da relação entre estes componentes empregados em uma determinada maneira de praticar a agricultura, confirma-se que os desajustes provocados pelas práticas culturais serão completamente diferentes em solos e climas temperados ou tropicais. Se pensarmos a fertilidade como o potencial de nutrientes disponíveis em um solo sem considerar a relação deste com os vegetais e o clima que com ele se relacionam, a aplicação do conceito perde o seu sentido. Nesta aplicação, por exemplo, os solos que sustentam uma floresta nativa na Amazônia não sustentam uma pastagem, ou uma cultura temporária repetida por alguns anos, 0 que se torna contraditório. Os nutrientes que estão nos vegetais e animais que compõem o sistema são considerados como um atributo do solo, embora tenham passagem por ele quando em determinadas etapas do ciclo de nutrientes. Qualquer 
alteração no arranjo entre eles promoveria uma translocação imediata dos nutrientes, parte para fora do mesmo, através da erosão ou transporte, e parte para as profundezas, via lixiviação. A fertilidade, assim, só tem sentido se pensada como atributo de um sistema complexo e não de um componente com função de substrato temporário dos nutrientes, no caso o solo. Ao se lhe atribuir uma utilização pelo homem, este uso pressupõe uma tecnologia e suas consequências, como o grau de exposição aos outros fatores climáticos (insolação, pluviosidade, agentes macrobiológicos, microbiológicos e químicos). Neste caso, a queima pode oferecer a oportunidade de frases afirmativas como: $o$ único aporte importante de nutrientes é feito pela queimada (Fabri, Veiga Jr. e Ozier Lafontaine, 1991, p. 147).

Contextualizando, nos plantios de arroz feitos na Amazônia, diagnosticados pelos autores acima, o aproveitamento dos nutrientes pela cultura temporária implantada nos primeiros anos é satisfatório, o que não pode ser afirmado se os cultivos continuarem a ser feitos nos anos seguintes (Kato e outros, 1999).

Qualquer trabalho sobre agricultura na Amazônia precisa, portanto, de uma crítica fina do conceito de fertilidade naquele contexto.

A importância dada à matéria orgânica na agricultura, antes das descobertas de Liebig sobre os fertilizantes químicos, assim como o ritmo em que se dava a produção agrícola, induzia a pensar a fertilidade como um atributo combinado de fatores do meio ambiente, ainda que a terra fosse considerada como o principal fornecedor de nutrientes desde tempos imemoriais. A adubação química e a redução da agricultura a uma atividade que poderia adquirir uma lógica submissa aos paradigmas da revolução industrial deu as coordenadas para se pensar o solo como insumo básico, principal, neste tipo de prática social. Os manuais de fertilização do solo (Coelho e Verlengia, s/d.) apresentam a planta como ator principal deste processo e os fatores que afetam o seu crescimento (temperatura, luz, água, ar e nutrientes) como insumos necessários ao seu crescimento.

O termo fertilidade refere-se à capacidade de um solo para fornecer nutrientes às plantas em quantidades adequadas e proporções convenientes (Coelho e Verlengia, s/d, p. 7).

Mazoyer define a fertilidade global de um ecossistema como a sua capacidade de produzir, de forma durável, biomassa vegetal (Mazoyer, 1997, p. 50). Distingue a fertilidade global da fertilidade útil como sendo a capacidade de produzir desenvolvimento de materiais orgânicos vegetais úteis ao homem ou aos animais domésticos, ou seja, colheitas (Mazoyer, 1997, p. 22). 
A relação solo planta como determinante na prática de agricultores pode ser encontrada desde a literatura mais antiga, de forma que, fundada como parâmetro, ainda permanece mesmo depois da onda de críticas que introduziu os conceitos holisticos da ecologia moderna como novo paradigma.

De fato, o que é necessário é se reconstruir toda a análise dos discursos anteriores onde uma compreensão mais abrangente era fornecida, sendo reduzida próxima a uma relação química depois das descobertas de Liebig. O importante é frisar que se é verdade que os elementos químicos são importantes no rendimento físico das culturas, é a sua combinação com outros fatores e o seu resultado o que deve ser priorizado como referência.

Um discurso coerente porém só se constrói com um arcabouço teórico capaz de lhe dar sustentação. O investimento em experimentos sob novas formas de relação com a natureza estabelecem novos parâmetros de abordagem, o que tem se verificado nas últimas décadas, passando-se de um conceito estático de fertilidade para noções mais dinâmicas, como a de sustentabilidade, onde se contempla principalmente o ciclo dos nutrientes e seu retorno ao sistema produtivo.

Entre os agrônomos, os congressos da década de 80 marcaram um novo posicionamento frente aos paradigmas assumidos quando da Revolução Verde, implicando um movimento por uma agricultura alternativa, no sentido de evitaro uso acrítico de insumos de qualquer natureza.

Não apenas os conceitos de fertilidade e sustentabilidade merecem crítica, mas todos os outros que, tomados a priori, apresentem limites explicativos aos problemas identificados e em estudo.

\section{Bibliografia citada}

Fonte primária:

Códice 343 (1795 à 1803) - AHUM - Lisboa

AEARJ, FAEAB. (1984), Agricultura Alternativa. Homem Natureza Namorando a Terra. II Encontro Brasileiro de Agricultura Alternativa. Petrópolis, FAEAB/AEARJ.

ALTIERI, M. A. (1989), Agroecologia: as bases científicas da agricultura alternativa. Rio de Janeiro: PTA/FASE.

ANDERSON, SCOTT D. (1991), Engenhos na várzea: uma análise de declinio de um sistema de produção tradicional na Amazônia in: Phillippe Léna \& Adélia Engrácia de Oliveira (orgs). Amazônia. A fronteira agticola 20 anos depois. Belém, Museu Paraense Emílio Goeldi, (Coleção Eduardo Galvão). 
ANGELO-MENEZES, Maria de Nazaré. (1998), Histoire sociale des systlimes agraires dans la vallée du Tocantins - Etat du Pará - Brésil. colonisation européenne dans la deuxieme moitié du XVIII siecle et la premiere moitié du XIX siecle. Paris, EHESS, (Thése du Doctorat).

ANGELO-MENEZES, Maria de Nazaré. (1999), O Sistema Agrário do Vale do Tocantins Colonial: agricultura para consumo e para exportação in Revista Projeto Historia: Espaço e Cultura, $\mathrm{n}^{\circ}$ 18. São Paulo, EDUC, PUC São Paulo,

ANGELO-MENEZES, Maria de Nazaré; REYNAL, Vincent de; WAMBERGUE, Emmanuel. (1989), Recherche-Developpement en Amazonie: formalisation du savoir des agriculteurs. Caribbean Food Croops Sociery, Guadeloupe,.

CAMINHA, Pero Vaz de. (1987), Carta de Pero Vaz de Caminha a EI-Rry D. Manuel sobre o achamento do Brasil. Portugal, Ed. Europa América, (Coleção Livros de Bolso Europa América).

CARDOSO, A., MARTINS, P. F. S. \& VEIGAJR., L (1991), Solos de áreas ocupadas por pequenos agricultores em algumas localidades da microregião de Marabá-Pará. Agricultures Pqysannes et Développement: Caraibe-Amérique tropicale. Atas do Seminário Agricultura Familiar e Desenvolvimento Rural na Amazônia Oriental Pointe-à-pitre, Université des Antilles et de Ia Guyane, 101-137.

COELHO, Fernando S. e VERLENGIA, Flávio. (s/d.), Fertilidade do Solo. Campinas, Instituto Campineiro de Ensino Agrícola,

DOMINGUEZ, Camilo. (1980), La Amazónia Colombiana dentro de la Amazónia Occidental Conferência. Belém, Núcleo de Altos Estudios Amazónicos, NAEA, Nov. 27.

FABRI, Claude, VEIGAJr., Iram et OZIER-LAFONTAINE, Harry. (1991), Diagnóstico Agronômico do arroz na região de Marabá (Pará-Brasil), primeiros resultados e metodologia. Agricultures Paysannes et Dévéloppement: Caraibe-Amérique tropicale. Actes du Seminaire d'Agriculture Familiale et Dévéloppement Rural en Amazonie Orientale. Point-à-. Pitre, Université des Antilles et de Ia Guyanne,. p. 141-158. (Hors Serie).

FAEAB, FEAB, AEAMT e CAAUFMT. (1987), Agricultura Alternativa. III Encontro Brasileiro de Agricultura Alternativa. Anais... Cuiabá, FAEAB, FEAB, AEAMT e CAAUFMT.

FEARNSIDE, Philip Martin. (1989), Agricultura na Amazônia. Tipos de agricultura: padrões e tendências. Cadernos do NAEA 10: 197-252. Belém, NAEA/UFPa,

GUERRA, G.A.D. (1999), Chercheurs et Syndicalistes pour un Autre Developpement Rural L'expérience d'une recherche-action dans l'Etat du Pará - Brésil Paris, Ecole des Hautes Etudes en Sciences Sociales/Centre d'Etudes des Mouvements Sociaux, (Sous Ia direction de Mme. Rose-Marie LAGRAVE).

KATO, M. S. A; LATO, O. R.; DENICH, M. e VVLEK, P. L. G. (1999), Fire-free alternatives to slash-and-burn for shifting cultivation in the eastern Amazon Region: the role of fertilizers. Field Crops Research, (62); 225-237. Amsterdan, EIsevier S>:ience.

KLINGE, H. Adis; FURCH, K. y JUNK, W J. (1987), Algunos elementos básicos del eco sistema amazônico in Homem e Natureza na Amazônia. Tubinger, Geofrapische Studien, Tubinger. .

LUGO, Ariel. y Morris Gregory. (1982), Los sistemas ecológicos y la humanidad. Washinton, Secretaria General de Ia OEA. 
MAZOYER, Marcel e ROUDART, Laurence. (1997), Histoire des Agricultures du Monde. Du néolitique à la crise contemporaine. Paris, Seuil.

MOREIRA, Eidorfe. (1960), Amazônia. O conceito e a paisagem. Rio de Janeiro, SPVEA, NEVES A. Walter. (org.). (1991), Origens, adaptações e diversidade biológica do homem nativo da Amazônia. Belém, MPEG/CNPq/PR, 192p. (Coleção Emilie Sneth1age).

ODUM, Eugene P. (1988), Ecologia. Rio de Janeiro, Editora Guanabara.

PRIMAVESI, Ana Maria. (1985), Manejo Ecológico de Pastagens 2ed. São Paulo, Nobel PRODIAT. (1985). Perfis indicativos para a industrialização do arroz milho e soja. Brasília, $\mathrm{s} / \mathrm{Ed}$.

REYNAL, V. de; MUCHAGATA, M.; TOPALL, O; HEBETTE, J. (s.d.), Agriculturas Familiares e desenvolvimento em frente pioneira amazônica. Belém/Paris/Pointe-à-Pitre, LASAT- CAT/GRET/DAT-UAG.

ROOSEVELT, Anna C. (1980), PARMANA.. Prehistoric maize and mamac subsistence along the Amazon and Orinoca. Academic Press Inc. New York.

ROOSEVELT, Anna C. (1991), Determinismo ecológico na interpretação do desenvolvimento social indígena da Amazônia in: Neves A. Walter. (org.). Origens, adaptações e diversidade biológica do homem nativo da Amazônia. Belém, MPEG/CNPq/PR,. (Coleção Emilie Snethlage).

SALATI, Eneas (1987), Amazônia: um ecossistema ameaçado, in: Homem e natureza na Amazônia. Tubinger Geogrqpishe studien. Tubinger.

SALLIS, Annette. (1987), Economie pqysanne et integration au marché - évolution des formations agraires des hautes vallées interandines de Cusco. Paris, INA-PG (Thése du doctorat), $2^{\circ}$. v., p. 4.

SMITH, Roberto. (1990), Propriedade da terra e Transição. Estudo da formação da propriedade privada da terra e transição para o capitalismo no Brasil. São Paulo, Ed. Brasiliense.

TOPALL, Olivier (1990), Colonisation Agricole au long de la Transamazonienne. Les !)s\#mes de production 20 ans aPreso Une étude de caso Marabá- Brésil Rennes, Ecole Nationale Supérieure d'Agronornie de Rennes.

VIEIRA, Lúcio Salgado. (1988), Manual de Ciência do Solo: com ênfase em solos tropicais, 2ed. São Paulo, Agronômica Ceres.

WAISCHET, Wolfang. (1987), Las condiciones climaticas en la Amazonia in: Homem e Natureza na Amazônia. Tubingen Geographische. Tubingen. 